\title{
Alkaloid production by isolates of the sorghum ergot pathogen (Claviceps africana) from Australia and other countries
}

\author{
Barry Blaney $^{\mathrm{A}, \mathrm{C}}$, Sukumar Chakraborty ${ }^{\mathrm{B}}$, and Sally-Ann Murray ${ }^{\mathrm{A}}$ \\ ${ }^{A}$ Department of Primary Industries and Fisheries, Locked Mail Bag No. 4, Moorooka, Qld 4105, Australia. \\ ${ }^{B}$ CSIRO Plant Industry, Queensland Bioscience Precinct, 306 Carmody Road, St Lucia, Qld 4067, Australia. \\ ${ }^{\mathrm{C}}$ Corresponding author. Email: Barry.Blaney@dpi.qld.gov.au
}

\begin{abstract}
Isolates of Claviceps africana from Australia, Africa, Asia, and America were tested for the production of dihydroergosine (DHES), and its biogenic precursors dihydroelymoclavine (DHEL) and festuclavine (FEST), in culture. Several growth media were evaluated to optimise alkaloid production with little success. The best of these involved 2-stage culturing on high-sucrose substrate. Australian C. africana isolates varied widely and inconsistently in alkaloid production, with DHES concentrations in mycelium ranging from: $<0.1$ to $9 \mathrm{mg} \mathrm{DHES} / \mathrm{kg}$; $<0.1$ to $1.6 \mathrm{mg} \mathrm{DHEL} / \mathrm{kg}$; and $<0.1$ to $0.4 \mathrm{mg} \mathrm{FEST} / \mathrm{kg}$. In a separate experiment using similar culturing techniques, DHES was produced by 2 of 3 Australian isolates, 1 of 3 USA isolates, 1 of 4 Indian isolates, the sole Puerto Rican isolate, the sole Japanese isolate, but not the sole South African isolate. In this experiment, DHES concentrations detected in mycelium of Australian isolates $(0.1-1.0 \mathrm{mg} \mathrm{DHES} / \mathrm{kg}$ ) were of similar magnitude to isolates from other countries $(0.2-1.8 \mathrm{mg} \mathrm{DHES} / \mathrm{kg})$. Three $C$. africana isolates, including one that produced only traces of alkaloid in culture after 8 weeks, were inoculated onto panicles of sterile male sorghum plants. After 8 weeks, all 3 isolates produced $10-19 \mathrm{mg}$ DHES/kg in the panicles, demonstrating that the growing plant favoured more consistent alkaloid production than culture medium.
\end{abstract}

Additional keywords: mycotoxin, fungus, sclerotium, sphacelium.

\section{Introduction}

Sorghum ergot disease has long been known in Asia and Africa, but only recently detected in Australia and in South and North America. After infection, the ovaries of sorghum plants are replaced by a sporulating fungal stroma, the sphacelium, from which conidia-containing honeydew serves as the source of secondary infection. Subsequently, further tissue differentiation occurs in the sphacelium to eventually produce a hard sclerotium, a dormant structure able to withstand degradation in the environment. The sorghum ergot pathogen (anamorph, Sphacelia sorghi) was first observed in India (McRae 1917), and some years later in Africa. Kulkarni et al.(1976) recognised the perfect stage in India as Claviceps sorghi. Subsequently, the perfect stage of sorghum ergot in Africa was recognised as a distinct species and called Claviceps africana by Frederickson et al. (1991). A third species, Claviceps sorghicola has recently been described in Japan (Tsukiboshi et al. 1999). According to Frederickson et al. (1991), a primary distinguishing feature of C. africana is production of the alkaloid dihydroergosine (DHES; Mantle and Wright 1968), since they found other species causing sorghum ergot to produce little or none of this alkaloid. Tsukiboshi et al. (1999) reported that $C$. sorghicola produced low concentrations $(2 \mathrm{mg} / \mathrm{kg}$ in sclerotia) of a different alkaloid similar to paliclavine. Bogo and Mantle (2000) reported that the major alkaloid produced by $C$. sorghicola is caffeine, and that $C$. sorghi also produces caffeine.

Since its explosive worldwide spread, molecular markers have been used to identify specific strains of $C$. africana and their movement around the globe. Different populations and lineages have been reported from different parts of the world and from within a country (Pazoutova et al. 2000). For instance, a number of polymorphisms exist in the United States, indicating that the recently introduced population contains multiple genotypes (Tooley et al. 2000). Australian isolates have been delineated into 2 different clusters, but both appear to have originated on the Indian subcontinent (Komolong et al. 2002) rather than Africa. Isolates from Australia have been identified as C. africana, based on morphology (Ryley and Henzell 1997), molecular analysis (Komolong et al. 2002), and production of DHES (Blaney et al. 2003).

The first report of disease in livestock caused by sorghum ergot was of impaired milk production and feed refusal in sows and cows, which occurred in Queensland in 1997 (Blaney et al. 2000). More recently in 2003, 
cattle in several Queensland feedlots suffered severe losses from hyperthermia due to sorghum ergot (Blaney et al., unpublished data). Feeding trials have demonstrated that sorghum infected with $C$. africana can produce many of the same toxic effects as rye ergot (C. purpurea) in pigs and cattle (Blaney et al. 2001). In contrast, reports from overseas (Frederickson et al. 1991) indicated very low toxicity to mice of $C$. africana sclerotia compared with those of C. purpurea. This raised questions of whether Australian isolates of $C$. africana are more toxigenic than those from other continents. The profile of alkaloids in collections of Australian sphacelia/sclerotia was predominantly DHES (Blaney et al. 2003), which is consistent with some African isolates (Frederickson et al. 1991). However, the concentrations found in Australian sclerotia varied widely, which could account for variable toxicity. The differences found in sclerotia might arise from inherent differences in the toxigenic potential of the isolates, or else from different environmental factors. We wished to establish standard culturing procedures to compare in vitro alkaloid production of isolates from different Australian regions with some isolates from other countries.

A process for inducing alkaloid production in vitro would also be useful for distinguishing strains of Claviceps species, although large numbers of isolates would need to be examined to see how consistently this matches other aspects of taxonomy. However, there are several challenges in the production of mycotoxins in culture. Firstly, there is the issue of achieving optimal mycelial growth; secondly, genetically identical isolates express secondary metabolism under different environmental conditions, often under conditions of specific nutrient limitation. Claviceps species are known to be particularly fickle in regard to expression of alkaloid production in culture: the lengthy investigations by pharmaceutical companies seeking to facilitate this process have been reviewed by Minghetti and Crespi-Perellino (1999). In many studies, despite luxurious growth in culture, only traces of alkaloid were detected. Selection of $C$. purpurea strains for industrial production was finally achieved by screening many thousands of mycelial fragments, and re-screening subfragments of the most productive fragments. Mantle and Tonolo (1968) compared the morphology of alkaloid-productive and non-productive strains of C. purpurea and found that an alkaloid-productive strain was distinguished by development of sclerotium-like tissue in culture.

Mantle (1973) took a similar approach of lengthy selection processes to identify a strain of sorghum ergot (described only as Sphacelia sorghi) from Nigeria that produced sclerotiallike tissue and high concentrations of DHES in culture, with lesser amounts of dihydroelymoclavine (DHEL) and festuclavine (FEST), the latter alkaloids being biogenic precursors of DHES (Barrow et al. 1974). However, he considered it possible that sphacelial hyphae could also synthesise alkaloids, and that the correlation between alkaloid production and sclerotial tissue was not as absolute as in C. purpurea. This offered the possibility that alkaloid production in vitro by sorghum ergot isolates could be an indication of subsequent production within sclerotia, both for chemo-taxonomic purposes and as a guide to potential toxicity to livestock.

Once a strain of $C$. purpurea producing high alkaloid concentrations was identified, a very high sucrose concentration $(30 \%)$ in culture maximised alkaloid production (Amici et al. 1967), and a similar result was obtained by Mantle (1973) for C. africana. Phosphate has a key role in alkaloid production (Kren 1999) and the optimum level ranges from 1 to $4 \mathrm{mM}$ in high-alkaloid-producing strains of $C$. purpurea. A drop in intracellular phosphate coincides with cessation of mycelial growth and the onset of alkaloid production (Arcamone et al. 1970; Pazoutova and Rehacek 1984), but high levels of phosphate induce alkaloid-degrading enzymes, lowering alkaloid yields (Robbers et al. 1978). Consequently, we explored the role of phosphate for optimising alkaloid production in vitro. We also considered that DHES production in inoculated sorghum ovaries might provide a guide to the effectiveness of our in vitro techniques.

The objectives of this investigation were as follows: to standardise conditions for fungal growth and alkaloid production in vitro; to compare in vitro alkaloid production by isolates of $C$. africana from different Australian regions, and to compare this with the production of alkaloids by isolates of C. africana, C. sorghicola, and C. sorghi from the USA, India, Japan, Puerto Rico, and South Africa; and to examine alkaloid production in inoculated sorghum ovaries by Australian strains having different in vitro alkaloid production ability.

\section{Materials and methods}

\section{Fungal isolates}

Australian isolates of $C$. africana were obtained from single conidia or single sphacelia and sclerotia obtained from different regions. Ten exotic isolates of C. africana, from the USA (3), India (4), Puerto Rico, Japan, and South Africa, were obtained as pure cultures and treated under normal quarantine restrictions. One isolate of C. sorghicola was obtained from Japan, and one of $C$. sorghi from India. Details are given by Komolong et al. (2002). Isolates were grown on potato dextrose agar (PDA), and maintained on agar discs in $15 \%$ glycerol in liquid nitrogen.

\section{Alkaloid assays}

Mycelial samples were either extracted directly, or after freeze-drying. If freeze-dried, $4 \mathrm{~g}$ of mycelium was reconstituted by blending for $1 \mathrm{~min}$ with $20 \mathrm{~mL}$ of water before extraction. Wet mycelium was blended with $10 \mathrm{~mL}$ of water. The extracts were made alkaline with aqueous ammonia ( $\mathrm{pH} 8.5-9)$, and extracted twice with $40 \mathrm{~mL}$ of methylene chloride. The extracts were combined and filtered through a phaseseparating paper with $5 \mathrm{~g}$ of anhydrous sodium sulfate. Culture filtrates $(20 \mathrm{~mL})$ were adjusted to $\mathrm{pH} 8.5-9$, and alkaloids were partitioned with blending into a single extract of $40 \mathrm{~mL}$ of methylene chloride, using centrifugation $(10 \mathrm{~min}$ at $3400 \mathrm{G}$ ) to resolve emulsions. Methylene chloride extracts were reduced to dryness under an air stream, dissolved 
in $1 \mathrm{~mL}$ of methanol, and filtered into a sealed vial. These were assayed using a Shimadzu LC-10 liquid chromatograph equipped with UV (SPD-M10A diode array) and fluorescence (RF-10A XL) detectors, as described by Blaney et al. (2003). Separation was on a Novopac (Waters) C18 column, operated isocratically at $40^{\circ} \mathrm{C}$, using acetonitrile: methanol:0.1\% ammonium acetate $(31: 20: 50)$. Results are expressed on the basis of wet, drained mycelium weight. Infected sorghum spikelets were comminuted in a high-speed blender, subsampled, and assayed by similar methods. Average ( \pm s.e.) recoveries of alkaloids spiked into culture broths at concentrations of either 1 or $5 \mathrm{mg} / \mathrm{L}$ were $93 \pm 0.90 \%$ for DHES, $79 \pm 0.84 \%$ for DHEL, and $88 \pm 0.95 \%$ for FEST.

\section{Experimental procedures}

Preliminary studies indicated that sorghum grain broth, V8 vegetable juice broth, and the medium of Bacon et al. (1979) were unsuitable for Claviceps spp., but satisfactory growth was obtained with the medium of Mantle (1973). Mantle's medium is composed of: sucrose $150 \mathrm{~g}$; L-asparagine $15 \mathrm{~g} ; \mathrm{KH}_{2} \mathrm{PO}_{4} 0.25 \mathrm{~g} ; \mathrm{MgSO}_{4} .7 \mathrm{H}_{2} \mathrm{O} 0.25 \mathrm{~g} ; \mathrm{FeSO}_{4} .7 \mathrm{H}_{2} \mathrm{O}$ $0.033 \mathrm{~g} ; \mathrm{ZnSO}_{4} .7 \mathrm{H}_{2} \mathrm{O} 0.027 \mathrm{~g}$; distilled water $1 \mathrm{~L}$; and adjusted to $\mathrm{pH} 5.5$.

\section{Alkaloid production on Mantle's medium and the effect} of phosphate depletion

This experiment compared mycelium growth and production of DHES by 6 C. africana isolates from north-eastern, central-eastern, and south-eastern Queensland in the medium of Mantle (1973). For each culture, $100 \mathrm{~mL}$ of medium was placed in a $500-\mathrm{mL}$ conical flask, covered with a cotton-wool plug, and autoclaved at $106^{\circ} \mathrm{C}$ for $20 \mathrm{~min}$. It was then inoculated with 2 disks (5-mm diam.) cut from a fungal culture grown on PDA, and the mycelium was teased out using sterile needles to encourage the growth of floating rafts of the fungus. The cultures were then incubated for 3 weeks at $27^{\circ} \mathrm{C}$ in the dark. Mycelial mats were carefully removed by decantation with the aid of a spatula, freeze-dried, and weighed, before storing at $-20^{\circ} \mathrm{C}$. Broth was also stored at $-20^{\circ} \mathrm{C}$ until assay.

The effect of phosphate depletion on alkaloid production was examined in 2 C. africana isolates from central-eastern (CQ15) and south-eastern Queensland (SE58A). The isolates were first grown in Mantle's medium as before for 3 weeks, and then the spent broth was decanted and replaced with a new batch of Mantle's medium, modified to contain various phosphate concentrations: $2 \mathrm{~mm}$ Mantle's standard concentration; $1 \mathrm{~mm} \mathrm{P} ; 0.5 \mathrm{~mm} \mathrm{P} ; 0.25 \mathrm{~mm}$ P; and zero P. It was incubated for a further 3 weeks. At the end of the second incubation, mycelium and broth were separated by decanting, weight of mycelium was recorded, and mycelium and broths from both incubations were stored at $-20^{\circ} \mathrm{C}$ until assayed for alkaloids. Cultures were duplicated, results were analysed using analysis of variance, and means were separated using Duncan's multiple range test.

\section{Alkaloid production by Australian and exotic isolates}

This experiment compared alkaloid production by 7 C. africana isolates from Queensland after 2-stage fermentation on Mantle's medium as above, but without phosphate depletion. The first incubation was for 3 weeks and the second incubation for 5 weeks. After replacing spent broth with fresh medium, the flask was shaken vigorously by hand until the submerged culture broke into floating fragments. At the end of the second incubation the mycelial mat was removed by decantation, rinsed with distilled water, and stored at $-20^{\circ} \mathrm{C}$ until assay. Broths from both incubations were also stored at $-20^{\circ} \mathrm{C}$.

Alkaloid production by 40 Australian and 12 exotic isolates of C. africana, plus reference isolates of C. sorghi and C. sorghicola, was studied in a separate experiment using the same procedure. All cultures were in triplicate, results were subjected to analysis of variance, and means were separated using Duncan's multiple range test.

\section{Alkaloid production in infected sorghum ovaries}

This experiment measured production of alkaloids in sorghum panicles, following artificial inoculation by each of 3 Australian isolates (NT32, CQ15, SEGRSO) that were relatively low, moderate, and high alkaloid producers, respectively, across the various in-vitro tests. The monoconidial culture of a single isolate was grown on PDA, blended into fragments, and inoculated onto flowering male-sterile sorghum panicles. When infection was established, honeydew was collected and stored in $15 \%$ glycerol at $-80^{\circ} \mathrm{C}$. A standardised inoculum concentration of $10^{6} \mathrm{conidia} / \mathrm{mL}$ was then obtained by mixing the stored honeydew with the necessary volume of distilled water. The panicles on 18 male-sterile sorghum plants (6 plants per isolate; cv. Wheatland) were inoculated upon flowering in a controlled environment cabinet $\left(27^{\circ} \mathrm{C}\right.$ day, $25^{\circ} \mathrm{C}$ night, and a $12-\mathrm{h}$ photoperiod). The inoculum was sprayed on using Preval pressure pack sprayers (Precision Valve Corp., Yonkers, New York) until run-off. The inoculated plants were incubated in a dew chamber for $48 \mathrm{~h}$ and then moved to a naturally illuminated glasshouse at ambient temperature. The honeydew was rinsed from the panicles to maintain clean spikelets free of contaminating fungi. Infected panicles were collected at 3 and 8 weeks after inoculation, to mirror the incubation times used in the in-vitro studies of the Australian isolates. Panicles from each plant were assayed separately to form 3 replicates for each isolate and sampling time. Statistical treatment was as in previous experiments.

\section{Results}

\section{Growth and alkaloid production on Mantle's medium}

The results in Table 1 give average DHES production data for 6 Australian isolates. Although mycelium growth of all isolates was comparable across replicates, their DHES production was generally low and variable. The isolate SEGRSO yielded relatively higher amounts of DHES, which was present in both mycelium and broth.

\section{Two-stage fermentation with phosphate depletion}

Compared with a single fermentation in Mantle's medium, mycelial production was increased by the 2-stage fermentation (Table 2). Isolate CQ15 produced moderate concentrations of DHES for all treatments regardless of the amount of phosphate in the replacement media. Although the

Table 1. Mycelium growth and dihydroergosine (DHES) production by isolates of $C$. africana from 3 regions of Queensland in the medium of Mantle (1973)

Results are the mean of duplicate cultures

\begin{tabular}{llcc}
\hline $\begin{array}{l}\text { Region and } \\
\text { isolate }\end{array}$ & $\begin{array}{l}\text { Wt mycelium } \\
(\mathrm{g} / \mathrm{L} \text { medium })\end{array}$ & $\begin{array}{c}\text { DHES } \\
(\mathrm{mg} / \mathrm{kg} \text { mycelium })\end{array}$ & $\begin{array}{c}\text { DHES } \\
(\mathrm{mg} / \mathrm{L} \text { broth })\end{array}$
\end{tabular}

\begin{tabular}{lrlr}
\hline South-eastern & & & \\
SE4 & 8 & 0.06 & $<0.1$ \\
SE58A & 15 & 0.3 & $<0.1$ \\
SE84B & 7 & 0.1 & $<0.1$ \\
SEGRSO & 15 & 6.4 & 0.7 \\
Central-eastern & & & $<0.1$ \\
$\quad$ CQ15 & 9 & 0.09 & \\
North-eastern & & & $<0.1$ \\
$\quad$ NQ58 & 8 & 0.05 & \\
\hline
\end{tabular}


Table 2. Effects of phosphate-depletion in the second stage of a 2-stage fermentation on dihydroergosine (DHES) production by an isolate of $C$. africana (CQ15)

Results are the mean of duplicate cultures. Within columns, differences are not significant $(P<0.05)$

\begin{tabular}{lcccrr}
\hline $\begin{array}{l}\text { Phosphate conc. } \\
\text { in stage } 2^{\mathrm{A}}\end{array}$ & $\begin{array}{c}\text { Wt mycelium } \\
(\mathrm{g} / \mathrm{L} \text { medium })\end{array}$ & $\begin{array}{c}\text { DHES } \\
(\mathrm{mg} / \mathrm{kg} \text { mycelium })\end{array}$ & $\begin{array}{c}\text { DHES } \\
(\mathrm{mg} / \mathrm{L} \text { broth })\end{array}$ & \multicolumn{2}{c}{$\begin{array}{c}\text { Total DHES }(\mu \mathrm{g}) \text { in: } \\
\text { Mycelium } \\
\text { Broth }\end{array}$} \\
\hline $2 \mathrm{~mm}$ P (control) & 23 & 8.8 & 3.7 & 85 & 370 \\
$1 \mathrm{~mm} \mathrm{P}$ & 25 & 2.1 & 1.1 & 27 & 110 \\
$0.5 \mathrm{~mm} \mathrm{P}$ & 22 & 2.5 & 0.9 & 29 & 85 \\
$0.25 \mathrm{~mm} \mathrm{P}$ & 18 & 0.7 & 0.2 & 9 & 23 \\
Zero P & 34 & 4.0 & 1.3 & 47 & 130
\end{tabular}

${ }^{\mathrm{A}}$ The medium was that of Mantle (1973) in the first stage (containing $2 \mathrm{~mm}$ phosphate), and the resultant

mycelium was re-incubated in a second batch of Mantle's medium in which the phosphate content was varied.

effect of phosphate was not statistically significant, highest concentrations were produced without phosphate depletion. In contrast, a second isolate, SE58A, produced no detectable alkaloid in any of the treatments, although mycelial growth was satisfactory (data not given).

\section{Alkaloid production by Australian isolates}

Seven of the 40 isolates screened using the 2-stage fermentation in Mantle's medium produced moderate amounts of alkaloids. Five of these 7 were collected in centraleastern Queensland and 2 in south-eastern Queensland. An additional 8 isolates from central-eastern Queensland, 18 from south-eastern Queensland, 1 from north-eastern Queensland, 3 from the Northern Territory, and 2 from New South Wales did not produce detectable alkaloids $(<0.1 \mathrm{mg} / \mathrm{kg})$ in mycelium under these conditions. Although all positive isolates were from central-eastern and southeastern Queensland, there were too few isolates from other locations for a valid comparison of toxigenic potential between regions.

Results are given only for the 7 positive isolates in Table 3. There were significant differences in alkaloid

Table 3. Production of dihydroergosine (DHES), dihydroelymoclavine (DHEL), and festuclavine (FEST) by isolates of $C$. africana from central-eastern (CQ) and south-eastern (SE) Queensland after a 2-stage fermentation in the medium of Mantle (1973)

Results are the mean of 3 replicates. Within columns, means followed by the same letter are not significantly different $(P<0.05)$ according to Duncan's multiple range test

\begin{tabular}{lcrrrrr}
\hline & \multicolumn{3}{c}{ Mycelium (mg/kg) } & \multicolumn{3}{c}{ Broth (mg/L) } \\
& DHES & DHEL & FEST & DHES & DHEL & FEST \\
\hline CQ6C & $4.9 \mathrm{ab}$ & $1.5 \mathrm{a}$ & 0.3 & $0.13 \mathrm{~b}$ & 0.10 & 0.01 \\
CQ10 & $1.3 \mathrm{~b}$ & $0.5 \mathrm{~b}$ & $<0.1$ & $0.10 \mathrm{~b}$ & 0.17 & 0.03 \\
CQ20 & $7.3 \mathrm{a}$ & $1.3 \mathrm{a}$ & 0.4 & $0.20 \mathrm{~b}$ & 0.09 & 0.02 \\
CQ21 & $0.4 \mathrm{~b}$ & $0.3 \mathrm{~b}$ & 0.2 & $0.12 \mathrm{~b}$ & 0.09 & 0.09 \\
CQ22 & $0.5 \mathrm{~b}$ & $0.2 \mathrm{~b}$ & 0.4 & $0.63 \mathrm{a}$ & 0.13 & 0.30 \\
SE10763 & $9.4 \mathrm{a}$ & $1.6 \mathrm{a}$ & 0.5 & $0.27 \mathrm{ab}$ & 0.16 & 0.21 \\
SEGRSO & $8.4 \mathrm{a}$ & $1.3 \mathrm{a}$ & 0.1 & $0.33 \mathrm{ab}$ & 0.23 & 0.04 \\
\hline
\end{tabular}

production among these isolates. The effect of broth/ mycelium and isolate, as well as the isolate*broth/mycelium interaction was significant for DHES and DHEL but none was significant for FEST. The production of all 3 alkaloids was always higher in mycelia than in broth, and there was a clear correspondence between alkaloids in mycelium and broth. The general pattern of alkaloid production observed in sorghum ergot sclerotia from Queensland (Blaney et al. 2003) was also observed in these cultures: DHES predominated, with smaller amounts of DHEL and FEST.

Alkaloids were not detected in the spent broths from the first incubation in Mantle's medium $(<0.01 \mathrm{mg} / \mathrm{L})$, whereas they were present in broth after the second incubation as shown in Table 3. This indicated that alkaloid production had increased as a result of the dual fermentation of the 7 isolates that produced alkaloids in this experiment, even though the process failed to induce alkaloid production in the other isolates.

\section{Alkaloid production by Australian v. exotic isolates}

The results of this experiment are in Table 4. Of the 10 exotic $C$. africana isolates, 1 of 3 from the USA, 1 of 4 from India, and the sole isolates from Puerto Rico and Japan produced detectable amounts of alkaloids at levels comparable with 2 of 3 Australian isolates used for comparison. The analysis of variance tested the effect of country, and Australian $v$. non-Australian isolates, and both factors were not significant $(P<0.05)$.

\section{Alkaloid production in infected sorghum ovaries}

The results are in Table 5. After 8 weeks, the ovaries of inoculated spikelets were replaced with a fungal mass or sphacelia, but no fully formed sclerotia were evident. Levels of DHES produced by all 3 isolates after 8 weeks were more than 20 -fold higher than in culture medium. DHES production by all 3 isolates was of a similar order, although SEGRSO produced the largest amounts in both experiments. 
Table 4. Production of dihydroergosine (DHES), dihydroelymoclavine (DHEL), and festuclavine (FEST) by isolates of $C$. africana, $C$. sorghicola, and $C$. sorghi from several countries after a 2-stage fermentation on the medium of Mantle (1973) Results are the mean of 3 replicate cultures

\begin{tabular}{lcrrrrrr}
\hline Country & Isolate & \multicolumn{3}{c}{ Mycelium (mg/kg) } & \multicolumn{3}{c}{ Broth (mg/L) } \\
& & DHES & DHEL & FEST & DHES & DHEL & FEST \\
\hline & & \multicolumn{3}{c}{ C. africana } \\
Australia & CQ15 & $<0.01$ & 0.07 & $<0.01$ & $<0.01$ & $<0.01$ & $<0.01$ \\
Australia & NT32 & 0.11 & 0.11 & $<0.01$ & 0.06 & 0.08 & 0.38 \\
Australia & SEGRSO & 1.03 & 0.26 & 0.02 & 0.93 & 0.51 & 0.01 \\
USA & Cla5 & 0.20 & 0.12 & 0.02 & 0.17 & 0.38 & 0.03 \\
USA & Cla10 & $<0.01$ & $<0.01$ & $<0.01$ & $<0.01$ & 0.03 & $<0.01$ \\
USA & K6(KG) & $<0.01$ & $<0.01$ & $<0.01$ & $<0.01$ & 0.03 & $<0.01$ \\
Puerto Rico & Cla14 & 0.19 & 0.04 & 0.01 & 0.08 & 0.35 & 0.02 \\
South Africa & Cla58 & $<0.01$ & $<0.01$ & $<0.01$ & $<0.01$ & $<0.01$ & $<0.01$ \\
Japan & Cla83 & 1.75 & 0.17 & 0.06 & 0.87 & 0.22 & 0.01 \\
India & KA61B & 0.25 & 0.06 & $<0.01$ & 0.33 & 0.24 & 0.02 \\
India & NI6 & $<0.01$ & $<0.01$ & 0.01 & $<0.01$ & $<0.01$ & 0.01 \\
India & SK7 & $<0.01$ & 0.02 & $<0.01$ & $<0.01$ & 0.01 & $<0.01$ \\
India & NI3 & $<0.01$ & $<0.01$ & $<0.01$ & $<0.01$ & $<0.01$ & $<0.01$ \\
& & \multicolumn{7}{c}{ C. sorghicola } & & & $<$ \\
Japan & Cjap31 & $<0.01$ & $<0.01$ & $<0.01$ & $<0.01$ & $<0.01$ & $<0.01$ \\
& & \multicolumn{7}{c}{ C. sorghi } & & & \\
India & MH74 & $<0.01$ & $<0.01$ & $<0.01$ & $<0.01$ & $<0.01$ & $<0.01$ \\
\hline
\end{tabular}

Table 5. Dihydroergosine ( $\mathrm{mg} / \mathrm{kg})$ production after 3 and 8 weeks, in sorghum panicles inoculated with isolates of $C$. africana from central-eastern Queensland (CQ), south-eastern Queensland (SE), and the Northern Territory (NT)

Results are the mean (range) of 3 replicates

\begin{tabular}{lcc}
\hline Isolate & \multicolumn{1}{c}{3 Weeks } & 8 Weeks \\
\hline CQ15 & $<0.01(<0.01-0.01)$ & $12.7(6-16)$ \\
NT32 & $0.22(0.2-0.5)$ & $10.2(7-15)$ \\
SEGRSO & $0.04(0.02-0.07)$ & $19.3(16-21)$ \\
\hline
\end{tabular}

\section{Discussion}

This work has for the first time compared the in vitro alkaloid production of Australian isolates of $C$. africana with those from other continents. Some isolates from the USA, India, Puerto Rico, and Japan produced DHES in similar (albeit low) concentrations to those produced by Australian isolates. A single South African isolate did not produce alkaloids, but little significance can be attached to this, since DHES production by C. africana was first identified in that continent. DHES, DHEL, and FEST were not detected in single isolate, confirmed as C. sorghi, collected in 2000 in India, nor in a single isolate of $C$. sorghicola from Japan. However, larger collections of sclerotia from these 3 species should be examined to confirm if production of these alkaloids is unique to C. africana.

In common with previous workers, we were unable to induce field isolates to produce high concentrations of alkaloid in culture. Despite stringently following a rigorous schedule that produced a consistent amount of mycelial growth, alkaloid production was highly variable between experiments and between replicates within experiments. The cause of this is apparently variation in alkaloid production potential within the mycelium itself (Mantle 1973), but we rejected the approach of extensive selection of mycelial fragments in order to find high-alkaloid-producing strains, as this could not be evenly applied to all isolates. We were able to increase alkaloid production within individual cultures by a dual fermentation, but this did not overcome the primary limitation of mycelial variation. In comparison, some endophytic species of Balansia, a genus in the same Family (F. Clavicipitales) as Claviceps, are not so fickle in ergot alkaloid production (Bacon et al. 1979).

Low in vitro alkaloid production has been partly attributed to a failure to produce sphacelial/sclerotial tissues that support alkaloid production in culture (Mantle 1973). However, alkaloids are present in honeydew (or spores contained in honeydew) at concentrations up to $10 \mathrm{mg}$ DHES $/ \mathrm{kg}$ (Blaney et al. 2003) from the early stages of infection and long before sclerotial tissue develops. Ergot bodies composed mainly of sphacelial tissues tend to contain $10-200 \mathrm{mg}$ DHES $/ \mathrm{kg}$, but concentrations in fully developed sclerotia can rise to $10000 \mathrm{mg}$ DHES $/ \mathrm{kg}$.

Alkaloid production per unit infected tissue increased many-fold in 3 Australian isolates artificially inoculated onto sorghum panicles, compared with in vitro, and results were less variable between replicates. However, quarantine restrictions did not allow a comparison with exotic isolates under similar conditions. The factor that promotes 
development of alkaloid-producing tissues in vivo but not in vitro by Claviceps species has not been identified, but given the long co-evolutionary relationship involved in the lifecycle of plant and fungus, the fungus might be responding to factors in the living plant that determine grain filling and maturation, rather than to simple nutritional changes.

\section{Conclusions}

These results do not provide evidence to suggest that Australian isolates of $C$. africana are more toxigenic than the isolates from other continents. Unless methods are found to induce isolates to produce sclerotial tissue in culture, any future investigations should concentrate on comparisons of alkaloid production in sorghum panicles under controlled conditions. Such studies might be extended to investigate the influence of climatic factors on the initiation and development of sclerotia since, apart from infection, this appears the most critical factor associated with livestock toxicity.

\section{Acknowledgments}

The work was funded in part by the Grains Research and Development Corporation. We deeply appreciate the expert technical assistance of Mr Ross Perrott and Mr Leonard Ford. Dr Paul Tooley, Dr Ranajit Bandyopadhyay, and Dr Birte Komolong provided cultures, for which we are also grateful.

\section{References}

Amici AM, Minghetti A, Scotti T, Spalla C, Tognoli L (1967) Ergotamine production in submerged cultures and physiology of Claviceps purpurea. Applied Microbiology 15, 597-602.

Arcamone F, Cassinelli G, Ferni G, Penco S, Pennella P, Pol C (1970) Ergotamine production and metabolism of Claviceps purpurea strain 275 FI in stirred fermenters. Canadian Journal of Microbiology 16, 923-931.

Bacon CW, Porter JK, Robbins JD (1979) Laboratory production of ergot alkaloids by species of Balansia. Journal of General Microbiology 113, 119-126.

Barrow KD, Mantle PG, Quigley FR (1974) Biosynthesis of dihydroergot alkaloids. Tetrahedron Letters 15, 1557-1560. doi: 10.1016/S0040-4039(01)93135-1

Blaney BJ, Kopinski JS, Murray SA, McLennan SR, Moss RJ, Downing JA, Dingle JG (2001) Research on the toxicity of sorghum ergot and its alkaloids. In 'Proceedings from the 4th Australian Sorghum Conference'. 5-8 February 2001, Kooralbyn. (Eds AK Borrell, RG Henzell) (CD-ROM, Range Media Pty Ltd)

Blaney BJ, Maryam R, Murray S-A, Ryley MJ (2003) Alkaloids of the sorghum ergot pathogen (Claviceps africana): assay methods for grain and feed and variation between sclerotia/sphacelia. Australian Journal of Agricultural Research 54, 167-175. doi: 10.1071/AR02095

Blaney BJ, McKenzie RA, Walters JR, Taylor LF, Bewg WS, Ryley MJ, Maryam R (2000) Sorghum ergot (Claviceps africana) associated with agalactia and feed refusal in pigs and dairy cattle. Australian Veterinary Journal 78, 102-107.
Bogo A, Mantle PG (2000) Caffeine: also a fungal metabolite Phytochemistry 54, 937-939. doi: 10.1016/S0031-9422(00) 00169-2

Frederickson DE, Mantle PG, de Milliano WAJ (1991) Claviceps africana sp. nov.; the distinctive ergot pathogen of sorghum in Africa. Mycological Research 95, 1101-1107.

Komolong B, Chakraborty S, Ryley M, Yates D (2002) Identity and genetic diversity of the sorghum ergot pathogen in Australia. Australian Journal of Agricultural Research 53, 621-628. doi: 10.1071/AR01135

Kren V (1999) Physiological regulation of ergot alkaloid production and special cultivation techniques. In 'Ergot: the genus Claviceps'. Vol. 6 of Medicinal and industrial plants - industrial profiles. (Eds V Kren, L Cvak) pp. 165-172. (Harwood Academic Publishers: Amsterdam, The Netherlands)

Kulkarni BGP, Seshadri VS, Hegde RK (1976) The perfect stage of Sphacelia sorghi (McRae). Mysore Journal of Agricultural Sciences 10, 288-298.

Mantle PG (1973) Production of ergot alkaloids in vitro by Sphacelia sorghi. Journal of General Microbiology 75, 275-281.

Mantle PG, Tonolo A (1968) Relationship between the morphology of Claviceps purpurea and the production of alkaloids. Transactions of the British Mycological Society 51, 499-505.

Mantle PG, Wright ES (1968) Dihydroergosine: a new naturally occurring alkaloid from the sclerotia of Sphacelia sorghi (McRae). Nature 218, 581-582.

McRae W (1917) Notes on some south Indian fungi. In 'Madras agricultural yearbook'. pp. 108-111. (Govt. of Madras, Madras Agricultural Department: Madras, India)

Minghetti A, Crespi-Perellino N (1999) The history of ergot. In 'Ergot: the genus Claviceps'. Vol. 6 of Medicinal and industrial plantsindustrial profiles. (Eds V Kren, L Cvak) pp. 1-24. (Harwood Academic Publishers: Amsterdam, The Netherlands)

Pazoutova SR, Bandyopadhyay R, Frederickson DE, Mantle PG, Frederiksen RA (2000) Relations among sorghum ergot isolates from the Americas, Africa, India and Australia. Plant Disease 84, 437-442.

Pazoutova S, Rehacek Z (1984) Phosphate regulation of phosphatases in submerged cultures of Claviceps purpurea 129 producing clavine alkaloids. Applied Microbiology and Biotechnology 20, 389-392.

Robbers JE, Eggert WW, Floss HG (1978) Physiological studies on ergot. Time factor influence on the inhibitory effect of phosphate and the induction effect of tryptophan on alkaloid production. Lloydia 41, 120-129.

Ryley M, Henzell R (1997) Sorghum ergot in Australia. In 'Proceedings of the Global Conference on Ergot of Sorghum'. (Eds CR Casela, JA Dahlberg) pp. 182-190. (Empresa Brazileira de Pesquisa Agropecuaria: Brazil)

Tooley PW, O'Neill NR, Goley ED, Carras MM (2000) Assessment of diversity in Claviceps africana and other Claviceps species by RAM and AFLP analyses. Phytopathology 90, 1126-1130.

Tsukiboshi T, Shimanuki T, Uematsu T (1999) Claviceps sorghicola sp. nov., a destructive ergot pathogen of sorghum in Japan. Mycological Research 103, 1403-1408. doi: 10.1017/ S0953756299008539

Manuscript received 21 September 2005, accepted 1 May 2006 